\title{
$\delta \mathrm{g}^{*}$-Continuous Functions in Topological Spaces
}

\author{
R.Sudha \\ Assistant Professor \\ SNS College of Technology \\ Coimbatore-43
}

\author{
K.Sivakamasundari \\ Associate Professor \\ Avinashilingam University for Women \\ Coimbatore-43
}

\begin{abstract}
The Aim of this paper is to introduce the new class of function called $\delta \mathrm{g}^{*}$-continuous function by using $\delta \mathrm{g}^{*}$-closed set and study their basic properties in topological spaces. We also investigate its relationship with other types of functions.
\end{abstract}

\section{Keywords and phrases}

Generalized closed sets, $\delta$-closure, $\delta$ g-closed sets and g-open sets.

Mathematics Subject classification: 54C08, $54 \mathrm{C} 10$.

\section{INTRODUCTION}

Different types of generalizations of continuous maps were introduced and studied by various authors in the recent development of topology. In 2011, Lellis Thivagar et. al., [10] introduced the notion of $\delta \hat{\mathrm{g}}$-continuity in topological spaces. A new weaker form of the closed sets called $\delta \mathrm{g}^{*}$-closed sets is introduced and investigated by Sudha et. al., [17]. In this paper, we study $\delta \mathrm{g}^{*}$-continuous maps as a new generalization of $\delta$ g-continuous and obtain their characterizations, properties and discuss the relationships with some other functions.

\section{PRELIMINARIES}

Throughout this paper $(\mathrm{X}, \tau)$ (or simple $\mathrm{X}$ ) represents topological space on which no separation axioms are assumed unless otherwise mentioned. For a subset $\mathrm{A}$ of $\mathrm{X}, \operatorname{cl}(\mathrm{A}), \operatorname{int}(\mathrm{A})$ and $\mathrm{A}^{\mathrm{c}}$ denote the closure of $\mathrm{A}$, the interior of $\mathrm{A}$ and the complement of A respectively. Let us recall the following definitions, which are useful in the sequel.

\subsection{Definition}

A subset $\mathrm{A}$ of a space $(\mathrm{X}, \tau)$ is called a

(i) semi-open set [11] if $\mathrm{A} \subseteq \operatorname{cl}(\operatorname{int}(\mathrm{A}))$.

(ii) $\alpha$-open set [16] if $\mathrm{A} \subseteq \operatorname{int}(\operatorname{cl}(\operatorname{int}(\mathrm{A})))$

(iii) regular open set [17] if $\mathrm{A}=\operatorname{int}(\mathrm{cl}(\mathrm{A}))$.

The complement of a semi open (resp. $\alpha$-open, regular open) set is called semi-closed (resp. $\alpha$-closed, regular closed). The semi-closure [5] (resp. $\alpha$-closure [16]) of a subset A of $(\mathrm{X}, \tau)$, denoted by $\operatorname{scl}(\mathrm{A})(\operatorname{resp} . \alpha \operatorname{cl}(\mathrm{A}))$ is defined to be the intersection of all semi-closed (resp. $\alpha$-closed) sets containing A. It is known that $\operatorname{scl}(\mathrm{A})($ resp. $\alpha c \mathrm{c}(\mathrm{A}))$ is a semiclosed (resp. $\alpha$-closed) set.

\subsection{Definition [19]}

The $\delta$-interior of a subset $\mathrm{A}$ of $\mathrm{X}$ is the union of all regular open sets of $X$ contained in $A$ and is denoted by $\operatorname{int}_{\delta}(A)$. The subset $A$ is called $\delta$-open if $A=\operatorname{int}_{\delta}(A)$. i.e., a set is $\delta$-open if it is the union of regular open set. The complement of a $\delta$-open set is called $\delta$-closed. Alternatively, a set $\mathrm{A} \subseteq \mathrm{X}$ is called $\delta$-closed if $\mathrm{A}=\mathrm{cl}_{\delta}(\mathrm{A})$, where $\operatorname{cl}_{\delta}(\mathrm{A})=\{\mathrm{x} \in \mathrm{X} ;$ int $(\mathrm{cl}(\mathrm{U})) \cap \mathrm{A} \neq \phi, \mathrm{U} \in \tau$ and $\mathrm{x} \in \mathrm{U}\}$.

\subsection{Definition}

A subset $\mathrm{A}$ of $(\mathrm{X}, \tau)$ is called

1) generalized closed (briefly g-closed) [12] if $\operatorname{cl}(\mathrm{A}) \subseteq \mathrm{U}$ whenever $\mathrm{A} \subseteq \mathrm{U}$ and $\mathrm{U}$ is open in $(\mathrm{X}, \tau)$.

2) $\delta$-generalized closed (briefly $\delta$ g-closed) [7] if $\mathrm{cl}_{\delta}(\mathrm{A}) \subseteq \mathrm{U}$ whenever $\mathrm{A} \subseteq \mathrm{U}$ and $\mathrm{U}$ is open in $(\mathrm{X}, \tau)$.

3) $\delta \mathrm{g}^{*}-\operatorname{closed}[18]$ if $\mathrm{cl}_{\delta}(\mathrm{A}) \subseteq \mathrm{U}$ whenever $\mathrm{A} \subseteq \mathrm{U}$ and $\mathrm{U}$ is a g-open set in $(\mathrm{X}, \tau)$.

4) $\delta \widehat{g}$-closed $[8]$ if $\operatorname{cl}_{\delta}(\mathrm{A}) \subseteq \mathrm{U}$ whenever $\mathrm{A} \subseteq \mathrm{U}$ and $\mathrm{U}$ is $\widehat{\mathrm{g}}$-open in $(\mathrm{X}, \tau)$.

5) $\alpha$-generalized closed (briefly $\alpha$ g-closed) [14] if $\alpha \mathrm{cl}(\mathrm{A}) \subseteq \mathrm{U}$ whenever $\mathrm{A} \subseteq \mathrm{U}$ and $\mathrm{U}$ is open in $(\mathrm{X}, \tau)$.

6) generalized $\alpha$ closed (briefly ga-closed) [13] if $\alpha \operatorname{cl}(\mathrm{A}) \subseteq \mathrm{U}$ whenever $\mathrm{A} \subseteq \mathrm{U}$ and $\mathrm{U}$ is $\alpha$-open in $(\mathrm{X}, \tau)$.

7) generalized closed (briefly g-closed) [12] if $\operatorname{cl}(\mathrm{A}) \subseteq \mathrm{U}$ whenever $\mathrm{A} \subseteq \mathrm{U}$ and $\mathrm{U}$ is open in $(\mathrm{X}, \tau)$.

8) semi-generalized closed (briefly sg-closed) [4] if $\operatorname{scl}(\mathrm{A}) \subseteq \mathrm{U}$ whenever $\mathrm{A} \subseteq \mathrm{U}$ and $\mathrm{U}$ is semi-open in $(\mathrm{X}, \tau)$.

9) generalized semi-closed (briefly gs-closed) [2] if $\operatorname{scl}(\mathrm{A})$ $\subseteq \mathrm{U}$ whenever $\mathrm{A} \subseteq \mathrm{U}$ and $\mathrm{U}$ is open in $(\mathrm{X}, \tau)$.

10) $\alpha \widehat{\mathrm{g}}$-closed [1] if $\alpha \mathrm{cl}(\mathrm{A}) \subseteq \mathrm{U}$ whenever $\mathrm{A} \subseteq \mathrm{U}$ and $\mathrm{U}$ is $\widehat{\mathrm{g}}$ - open in $(\mathrm{X}, \tau)$.

The complements of the above mentioned sets are called their respective open sets.

\subsection{Definition}

A map $f:(X, \tau) \quad(Y, \sigma)$ is called

1) $\delta \mathrm{g}$-continuous $[8]$ if $\mathrm{f}^{-1}(\mathrm{~V})$ is $\delta \widehat{\mathrm{g}}$-closed in $(\mathrm{X}, \tau)$ for every closed set $\mathrm{V}$ of $(\mathrm{Y}, \sigma)$.

2) $\alpha \widehat{\mathrm{g}}$-continuous [9] if $\mathrm{f}^{-1}(\mathrm{~V})$ is $\alpha \widehat{\mathrm{g}}$-closed in $(\mathrm{X}, \tau)$ for every closed set $\mathrm{V}$ of $(\mathrm{Y}, \sigma)$.

3) sg-continuous [12] if $f^{-1}(V)$ is sg-closed in $(X, \tau)$ for every closed set $\mathrm{V}$ of $(\mathrm{Y}, \sigma)$.

4) gs-continuous [3] if $\mathrm{f}^{-1}(\mathrm{~V})$ is gs-closed in $(\mathrm{X}, \tau)$ for every closed set $\mathrm{V}$ of $(\mathrm{Y}, \sigma)$.

5) ag-continuous [6] if $\mathrm{f}^{-1}(\mathrm{~V})$ is $\alpha \mathrm{g}$-closed in $(\mathrm{X}, \tau)$ for every closed set $\mathrm{V}$ of $(\mathrm{Y}, \sigma)$. 


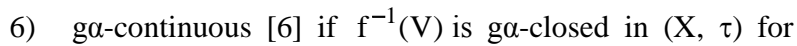
every closed set $\mathrm{V}$ of $(\mathrm{Y}, \sigma)$.

7) $\alpha$-continuous [15] if $\mathrm{f}^{-1}(\mathrm{~V})$ is $\alpha$-closed in $(\mathrm{X}, \tau)$ for every closed set $\mathrm{V}$ of $(\mathrm{Y}, \sigma)$.

8) g-continuous [12] if $\mathrm{f}^{-1}(\mathrm{~V})$ is g-closed in $(\mathrm{X}, \tau)$ for every closed set $\mathrm{V}$ of $(\mathrm{Y}, \sigma)$.

\subsection{Definition [18]}

A space $\mathrm{X}$ is called

1) ${ }_{\delta g} * \mathrm{~T}_{\delta}$-space if every $\delta \mathrm{g}^{*}$-closed set in it is closed.

2) ${ }_{\alpha \mathrm{g}} \mathrm{T}_{\delta \mathrm{g}^{*}}$-space if every $\alpha \mathrm{g}$-closed set in it is $\delta g^{*}-$ closed.

\section{$3.8 \mathrm{~g}^{*}$-CONTINUOUS FUNCTIONS}

In this section we introduce $\delta \mathrm{g}^{*}$-continuous map in topological spaces and study some of their properties. We prove that the composition of two $\delta \mathrm{g}^{*}$-continuous maps need not be $\delta \mathrm{g}^{*}$-continuous.

\subsection{Definition}

A map $\mathrm{f}:(\mathrm{X}, \tau) \longrightarrow(\mathrm{Y}, \sigma)$ is said to be $\delta \mathrm{g}^{*}$-continuous if the inverse image of every closed set in $(Y, \sigma)$ is $\delta \mathrm{g}^{*}$ closed in $(\mathrm{X}, \tau)$.

\subsection{Theorem}

A map $\mathrm{f}:(\mathrm{X}, \tau) \longrightarrow(\mathrm{Y}, \sigma)$ is $\delta \mathrm{g}^{*}$-continuous if and only if the inverse image of every open set in $(\mathrm{Y}, \sigma)$ is $\delta \mathrm{g}^{*}$-open in $(\mathrm{X}, \tau)$.

Proof: (Necessity) Let $\mathrm{f}:(\mathrm{X}, \tau) \longrightarrow(\mathrm{Y}, \sigma)$ be $\delta \mathrm{g}^{*}$ continuous and $\mathrm{U}$ be an open set in $(\mathrm{Y}, \sigma)$. Then $\mathrm{Y}-\mathrm{U}$ is closed in $(\mathrm{Y}, \sigma)$. Since $\mathrm{f}$ is $\delta \mathrm{g}^{*}$-continuous, $\mathrm{f}^{-1}(\mathrm{Y}-\mathrm{U})=\mathrm{X}-\mathrm{f}^{-1}(\mathrm{U})$ is $\delta \mathrm{g}^{*}$-closed in $(\mathrm{X}, \tau)$ and hence $\mathrm{f}^{-1}(\mathrm{U})$ is $\delta \mathrm{g}^{*}$-open in $(\mathrm{X}, \tau)$.

(Sufficiency) Assume that $\mathrm{f}^{-1}(\mathrm{~V})$ is $\delta \mathrm{g}^{*}$-open in $(\mathrm{X}, \tau)$ for each open set $\mathrm{V}$ in $(\mathrm{Y}, \sigma)$. Let $\mathrm{V}$ be a closed set in $(\mathrm{Y}, \sigma)$. Then $\mathrm{Y}-\mathrm{V}$ is open in $(\mathrm{Y}, \sigma)$. By assumption, $\mathrm{f}^{-1}(\mathrm{Y}-\mathrm{V})=\mathrm{X}-\mathrm{f}^{-1}(\mathrm{~V})$ is $\delta \mathrm{g}^{*}$-open in $(\mathrm{X}, \tau)$, which implies that $\mathrm{f}^{-1}(\mathrm{~V})$ is $\delta \mathrm{g}^{*}$-close in $(\mathrm{X}, \tau)$. Hence $\mathrm{f}$ is $\delta \mathrm{g}^{*}$ continuous.

\subsection{Proposition}

Every $\delta$-continuous map is $\delta \mathrm{g}^{*}$-continuous

Proof: Let $\mathrm{f}:(\mathrm{X}, \tau) \longrightarrow(\mathrm{Y}, \sigma)$ be a $\delta$-continuous map. Let $\mathrm{V}$ be any closed set in $(\mathrm{Y}, \sigma)$. Since $\mathrm{f}$ is a $\delta$-continuous map, $\mathrm{f}^{-1}(\mathrm{~V})$ is $\delta$-closed in $(\mathrm{X}, \tau)$. By Proposition 3.2.[18], every $\delta$-closed set is $\delta \mathrm{g}^{*}$-closed, $\mathrm{f}^{-1}(\mathrm{~V})$ is $\delta \mathrm{g}^{*}$-closed in $(\mathrm{X}, \tau)$. Therefore $\mathrm{f}$ is $\delta \mathrm{g}^{*}$-continuous.

The converse of the above Proposition need not be true as seen from the following example.

\subsection{Example}

Let $\mathrm{X}=\mathrm{Y}=\{\mathrm{a}, \mathrm{b}, \mathrm{c}\}$ with $\tau=\{\mathrm{X}, \phi,\{\mathrm{a}\},\{\mathrm{a}, \mathrm{b}\}\}$ and $\sigma=\{\mathrm{Y}$, $\phi,\{a, b\}\}$. Let $f:(X, \tau) \quad(Y, \sigma)$ be the identity map. Then $\mathrm{f}$ is $\delta \mathrm{g}^{*}$-continuous but not $\delta$-continuous, since for the closed set $\{\mathrm{c}\}$ in $(\mathrm{Y}, \sigma), \mathrm{f}^{-1}(\{\mathrm{c}\})=\{\mathrm{c}\}$ is $\delta \mathrm{g}^{*}$-closed but not $\delta$-closed in $(X, \tau)$.

\subsection{Proposition}

Let $\mathrm{f}:(\mathrm{X}, \tau) \longrightarrow(\mathrm{Y}, \sigma)$ be a $\delta \mathrm{g}^{*}$-continuous map and $(\mathrm{X}, \tau)$ be a ${ }_{\delta g *} \mathrm{~T}_{\delta}$-space. The $\mathrm{f}$ is $\delta$-continuous.

Proof: Let $\mathrm{V}$ be a closed set in $(\mathrm{Y}, \sigma)$. Since $\mathrm{f}$ is $\delta \mathrm{g}^{*}$-continuous, $\mathrm{f}^{-1}(\mathrm{~V})$ is $\delta \mathrm{g}^{*}$-closed in $(\mathrm{X}, \tau)$. Since $(\mathrm{X}, \tau)$ is a ${ }_{\delta \mathrm{g}^{*}} \mathrm{~T}_{\delta}$-space, $\mathrm{f}^{-1}(\mathrm{~V})$ is $\delta$-closed in $(\mathrm{X}, \tau)$. Hence $\mathrm{f}$ is $\delta$-continuous.

\subsection{Corollary}

Every $\delta \mathrm{g}^{*}$-continuous map is $\delta \mathrm{g}$-continuous.

Proof: Follows from the fact that every $\delta \mathrm{g}^{*}$-closed set is $\delta \mathrm{g}$ closed.

The converse of the above Proposition need not be true as seen from the following example.

\subsection{Example}

Let $\mathrm{X}=\mathrm{Y}=\{\mathrm{a}, \mathrm{b}, \mathrm{c}, \mathrm{d}\}$ with $\tau=\{\mathrm{X}, \phi,\{\mathrm{a}, \mathrm{b}\}\}$ and $\sigma=\{\mathrm{Y}$, $\phi,\{a, b, c\}\}$. Let $f:(X, \tau) \longrightarrow(Y, \sigma)$ be the identity map. Then $\mathrm{f}$ is $\delta \mathrm{g}$-continuous but not $\delta \mathrm{g}^{*}$-continuous, since for the closed set $\{\mathrm{d}\}$ in $(\mathrm{Y}, \sigma), \mathrm{f}^{-1}(\{\mathrm{~d}\})=\{\mathrm{d}\}$ is $\delta \mathrm{g}^{*}$-closed in $(\mathrm{X}, \tau)$.

\subsection{Proposition}

Every $\delta \mathrm{g}^{*}$-continuous map is $\delta \hat{\mathrm{g}}$-continuous

Proof: Let $\mathrm{f}:(\mathrm{X}, \tau) \longrightarrow(\mathrm{Y}, \sigma)$ be a $\delta \mathrm{g}^{*}$-continuous map. Let $\mathrm{V}$ be any closed set in $(\mathrm{Y}, \sigma)$. Since $\mathrm{f}$ is a $\delta \mathrm{g}^{*}$ continuous map, $\mathrm{f}^{-1}(\mathrm{~V})$ is $\delta \mathrm{g}^{*}$-closed in $(\mathrm{X}, \tau)$. By Proposition 3.20. [18], every $\delta \mathrm{g}^{*}$-closed set is $\delta \hat{\mathrm{g}}$-closed, $\mathrm{f}^{-1}(\mathrm{~V})$ is $\delta \hat{\mathrm{g}}$ closed in $(\mathrm{X}, \tau)$. Therefore $\mathrm{f}$ is $\delta \hat{\mathrm{g}}$-continuous.

The converse of the above Proposition need not be true as seen from the following example.

\subsection{Example}

Let $\mathrm{X}=\mathrm{Y}=\{\mathrm{a}, \mathrm{b}, \mathrm{c}\}$ with $\tau=\{\mathrm{X}, \phi,\{\mathrm{a}\}\}$ and $\sigma=\{\mathrm{Y}, \phi$, $\{\mathrm{a}\},\{\mathrm{a}, \mathrm{b}\}\}$. Let $\mathrm{f}:(\mathrm{X}, \tau) \longrightarrow(\mathrm{Y}, \sigma)$ be the identity map, then $\mathrm{f}$ is $\delta \hat{\mathrm{g}}$-continuous but not $\delta \mathrm{g}^{*}$-continuous, since for the closed set $\{b, c\}$ in $(Y, \sigma), f^{-1}(\{b, c\})=\{b, c\}$ is $\delta \hat{g}$-closed but not $\delta \mathrm{g}^{*}$-closed in $(\mathrm{X}, \tau)$.

\subsection{Proposition}

Every $\delta \mathrm{g}^{*}$-continuous map is $\alpha \mathrm{g}$-continuous

Proof: Let $\mathrm{f}:(\mathrm{X}, \tau) \longrightarrow(\mathrm{Y}, \sigma)$ be a $\delta \mathrm{g}^{*}$-continuous map. Let $\mathrm{V}$ be any closed set in $(\mathrm{Y}, \sigma)$. Since $\mathrm{f}$ is a $\delta \mathrm{g}^{*}$-continuous map, $\mathrm{f}^{-1}(\mathrm{~V})$ is $\alpha \mathrm{g}$-closed in $(\mathrm{X}, \tau)$, as every $\delta \mathrm{g}^{*}$-closed set is $\alpha$-closed [Proposition 3.14, [18]]. Therefore $\mathrm{f}$ is $\alpha \mathrm{g}$ continuous.

The converse of the above Proposition need not be true as seen from the following example.

\subsection{Example}

Let $\mathrm{X}=\mathrm{Y}=\{\mathrm{a}, \mathrm{b}, \mathrm{c}\}$ with $\tau=\{\mathrm{X}, \phi,\{\mathrm{a}\},\{\mathrm{a}, \mathrm{b}\}\}$ and $\sigma=\{\mathrm{Y}$, $\phi,\{b, c\}\}$. Let $f:(X, \tau) \longrightarrow(Y, \sigma)$ be defined by $f(a)=b$, $\mathrm{f}(\mathrm{b})=\mathrm{a}, \mathrm{f}(\mathrm{c})=\mathrm{c}$. Then $\mathrm{f}$ is $\alpha \mathrm{g}$-continuous but not $\delta \mathrm{g}^{*}$. 
continuous, since for the closed set $\{a\}$ in $(Y, \sigma)$, $\mathrm{f}^{-1}(\{\mathrm{a}\})=\{\mathrm{b}\}$ is $\alpha \mathrm{g}$-closed but not $\delta \mathrm{g}^{*}$-closed in $(\mathrm{X}, \tau)$.

\subsection{Proposition}

Let $\mathrm{f}:(\mathrm{X}, \tau) \longrightarrow(\mathrm{Y}, \sigma)$ be a $\alpha \mathrm{g}$-continuous map and $(\mathrm{X}, \tau)$ be a ${ }_{\alpha \mathrm{g}} \mathrm{T}_{\delta \mathrm{g} *}$-space. Then $\mathrm{f}$ is $\delta \mathrm{g}^{*}$-continuous.

Proof: Let $\mathrm{V}$ be a closed set in $(\mathrm{Y}, \sigma)$. Since $\mathrm{f}:(\mathrm{X}, \tau) \longrightarrow(\mathrm{Y}, \sigma)$ is $\alpha \mathrm{g}$-continuous, $\mathrm{f}^{-1}(\mathrm{~V})$ is ag-closed in $(X, \tau)$. Since $(X, \tau)$ is ${ }_{\alpha \mathrm{g}} \mathrm{T}_{\delta \mathrm{g}^{*}}$-space, $\mathrm{f}^{-1}(\mathrm{~V})$ is $\delta \mathrm{g}^{*}$ closed in $(\mathrm{X}, \tau)$. Hence $\mathrm{f}$ is $\delta \mathrm{g}^{*}$-continuous.

\subsection{Proposition}

Every $\delta \mathrm{g}^{*}$-continuous map is gs-continuous.

Proof: The proof follows from the fact that every $\delta \mathrm{g}^{*}$-closed set is gs-closed.

The converse of the above Proposition need not be true as seen from the following example.

\subsection{Example}

Let $\mathrm{X}=\mathrm{Y}=\{\mathrm{a}, \mathrm{b}, \mathrm{c}, \mathrm{d}\}$ with $\tau=\{\mathrm{X}, \phi,\{\mathrm{a}\},\{\mathrm{a}, \mathrm{b}\}\}$ and $\sigma=\{\mathrm{Y}, \phi,\{\mathrm{c}, \mathrm{d}\}\}$. Let $\mathrm{f}:(\mathrm{X}, \tau) \longrightarrow(\mathrm{Y}, \sigma)$ be defined by $\mathrm{f}(\mathrm{a})=\mathrm{a}, \mathrm{f}(\mathrm{b})=\mathrm{c}, \mathrm{f}(\mathrm{c})=\mathrm{d}, \mathrm{f}(\mathrm{d})=\mathrm{b}$. Then $\mathrm{f}$ is gs-continuous but not $\delta \mathrm{g}^{*}$-continuous, since for the closed set $\{\mathrm{a}, \mathrm{b}\}$ in $(Y, \sigma), f^{-1}(\{a, b\})=\{a, d\}$ is gs-closed but not $\delta g^{*}$-closed in $(\mathrm{X}, \tau)$

\subsection{Proposition}

Every $\delta \mathrm{g}^{*}$-continuous map is $\alpha \hat{\mathrm{g}}$-continuous.

Proof: The proof follows from the fact that every $\delta \mathrm{g}^{*}$-closed set is $\alpha \hat{\mathrm{g}}$-closed

The converse of the above Proposition need not be true as seen from the following example.

\subsection{Example}

Let $\mathrm{X}=\mathrm{Y}=\{\mathrm{a}, \mathrm{b}, \mathrm{c}, \mathrm{d}\}$ with $\tau=\{\mathrm{X}, \phi,\{\mathrm{a}, \mathrm{b}\}\}$ and $\sigma=\{\mathrm{Y}, \phi$, $\{\mathrm{b}\},\{\mathrm{b}, \mathrm{a}\}\}$. Let $\mathrm{f}:(\mathrm{X}, \tau) \longrightarrow(\mathrm{Y}, \sigma)$ be defined by $\mathrm{f}(\mathrm{a})=\mathrm{a}$ , $f(b)=d, f(c)=b, f(d)=c$. Then $f$ is $\alpha \hat{g}$-continuous but not $\delta \mathrm{g}^{*}$-continuous, since for the closed set $\{\mathrm{c}, \mathrm{d}\}$ in $(\mathrm{Y}, \sigma)$, $\mathrm{f}^{-1}(\{\mathrm{c}, \mathrm{d}\})=\{\mathrm{b}, \mathrm{d}\}$ is $\alpha \hat{\mathrm{g}}$-closed but not $\delta \mathrm{g}^{*}$-closed in $(\mathrm{X}, \tau)$.

\subsection{Remark}

The following examples show that the notions of $\delta \mathrm{g}^{*}-$ continuity and $g \alpha$-continuity are independent.

\subsection{Example}

Let $\mathrm{X}=\mathrm{Y}=\{\mathrm{a}, \mathrm{b}, \mathrm{c}\}$ with $\tau=\{\mathrm{X}, \phi,\{\mathrm{a}\}\}$ and $\sigma=\{\mathrm{Y}, \phi,\{\mathrm{b}, \mathrm{c}\}\}$. Let $\mathrm{f}:(\mathrm{X}, \tau) \longrightarrow(\mathrm{Y}, \sigma)$ be defined by $\mathrm{f}(\mathrm{a})=\mathrm{b}, \mathrm{f}(\mathrm{b})=\mathrm{a}, \mathrm{f}(\mathrm{c})=\mathrm{c}$. Then $\mathrm{f}$ is $\mathrm{g} \alpha$-continuous but not $\delta \mathrm{g}^{*}$-continuous, since for the closed set $\{\mathrm{a}\}$ in $(\mathrm{Y}, \sigma)$, $\mathrm{f}^{-1}(\{\mathrm{a}\})=\{\mathrm{b}\}$ is $\mathrm{g} \alpha$-closed but not $\delta \mathrm{g}^{*}$-closed in $(\mathrm{X}, \tau)$.

\subsection{Example}

Let $\mathrm{X}=\mathrm{Y}=\{\mathrm{a}, \mathrm{b}, \mathrm{c}\}$ with $\tau=\{\mathrm{X}, \phi,\{\mathrm{a}\},\{\mathrm{a}, \mathrm{b}\}\}$ and $\sigma=\{\mathrm{Y}, \phi,\{\mathrm{c}\}\}$. Let $\mathrm{f}:(\mathrm{X}, \tau) \longrightarrow(\mathrm{Y}, \sigma)$ be defined by $f(a)=b, f(b)=c, f(c)=a$. Then $f$ is $\delta g^{*}$-continuous but not $\mathrm{g} \alpha$-continuous, since for the closed set $\{\mathrm{a}, \mathrm{b}\}$ in $(\mathrm{Y}, \sigma)$ $\mathrm{f}^{-1}(\{\mathrm{a}, \mathrm{b}\})=\{\mathrm{a}, \mathrm{c}\}$ is $\delta \mathrm{g}^{*}$-closed but not $\mathrm{g} \alpha$-closed in $(\mathrm{X}, \tau)$.

\subsection{Remark}

The following examples show that the notions of $\delta g^{*}$. continuity and sg-continuity are independent.

\subsection{Example}

Let $\mathrm{X}=\mathrm{Y}=\{\mathrm{a}, \mathrm{b}, \mathrm{c}\}$ with $\tau=\{\mathrm{X}, \phi,\{\mathrm{a}\},\{\mathrm{b}\},\{\mathrm{a}, \mathrm{b}\}\}$ and $\sigma$ $=\{\mathrm{Y}, \phi,\{\mathrm{a}\},\{\mathrm{a}, \mathrm{b}\}\}$. Let $\mathrm{f}:(\mathrm{X}, \tau) \longrightarrow(\mathrm{Y}, \sigma)$ be the identity map. Then $\mathrm{f}$ is sg-continuous but not $\delta \mathrm{g}^{*}$-continuous, since for the closed set $\{b\}$ in $(Y, \sigma), f^{-1}(\{b\})=\{b\}$ is sg -closed but not $\delta \mathrm{g}^{*}$-closed in $(\mathrm{X}, \tau)$.

\subsection{Example}

Let $\mathrm{X}=\mathrm{Y}=\{\mathrm{a}, \mathrm{b}, \mathrm{c}\}$ with $\tau=\{\mathrm{X}, \phi,\{\mathrm{a}\},\{\mathrm{a}, \mathrm{b}\}\}$ and $\sigma=\{\mathrm{Y}, \phi,\{\mathrm{c}\}\}$. Let $\mathrm{f}:(\mathrm{X}, \tau) \longrightarrow(\mathrm{Y}, \sigma)$ be defined by $\mathrm{f}(\mathrm{a})=\mathrm{b}, \mathrm{f}(\mathrm{b})=\mathrm{c}, \mathrm{f}(\mathrm{c})=\mathrm{a}$. Then $\mathrm{f}$ is $\delta \mathrm{g}^{*}$-continuous but not sg-continuous, since for the closed set $\{a, b\}$ in $(Y, \sigma)$, $\mathrm{f}^{-1}(\{\mathrm{a}, \mathrm{b}\})=\{\mathrm{a}, \mathrm{c}\}$ is $\delta \mathrm{g}^{*}$-closed but not sg-closed in $(\mathrm{X}, \tau)$.

\subsection{Remark}

The following examples show that the notions of $\delta \mathrm{g}^{*}$-continuity and $\alpha$-continuity are independent.

\subsection{Example}

Let $\mathrm{X}=\mathrm{Y}=\{\mathrm{a}, \mathrm{b}, \mathrm{c}, \mathrm{d}\}$ with $\tau=\{\mathrm{X}, \phi,\{\mathrm{a}\}\}$ and $\sigma=\{\mathrm{Y}, \phi$, $\{a, b, d\}\}$. Let $f:(X, \tau) \longrightarrow(Y, \sigma)$ be defined by $f(a)=d$, $\mathrm{f}(\mathrm{b})=\mathrm{c}, \mathrm{f}(\mathrm{c})=\mathrm{b}, \mathrm{f}(\mathrm{d})=\mathrm{a}$. Then $\mathrm{f}$ is $\alpha$-continuous but not $\delta \mathrm{g}^{*}$-continuous, since for the closed set $\{\mathrm{c}\}$ in $(\mathrm{Y}, \sigma)$, $\mathrm{f}^{-1}(\{\mathrm{c}\})=\{\mathrm{b}\}$ is $\alpha$-closed but not $\delta \mathrm{g}^{*}$-closed in $(\mathrm{X}, \tau)$.

\subsection{Example}

Let $\mathrm{X}=\mathrm{Y}=\{\mathrm{a}, \mathrm{b}, \mathrm{c}, \mathrm{d}\}$ with $\tau=\{\mathrm{X}, \phi,\{\mathrm{a}, \mathrm{b}\}\}$ and $\sigma=\{\mathrm{Y}, \phi,\{\mathrm{c}\}\}$. Let $\mathrm{f}:(\mathrm{X}, \tau) \longrightarrow(\mathrm{Y}, \sigma)$ be defined by $\mathrm{f}(\mathrm{a})=\mathrm{c}, \mathrm{f}(\mathrm{b})=\mathrm{d}, \mathrm{f}(\mathrm{c})=\mathrm{a}, \mathrm{f}(\mathrm{d})=\mathrm{b}$. Then $\mathrm{f}$ is $\delta \mathrm{g}^{*}$-continuous but not $\alpha$-continuous, since for the closed set $\{a, b, d\}$ in $(\mathrm{Y}, \sigma), \quad \mathrm{f}^{-1}(\{\mathrm{a}, \mathrm{b}, \mathrm{d}\})=\{\mathrm{b}, \mathrm{c}, \mathrm{d}\}$ is $\delta \mathrm{g}^{*}$-closed but not $\alpha$-closed in $(\mathrm{X}, \tau)$

\subsection{Remark}

The composition of two $\delta \mathrm{g}^{*}$-continuous maps need not be $\delta \mathrm{g}^{*}$-continuous as seen from the following example.

\subsection{Example}

Let $\mathrm{X}=\mathrm{Y}=\{\mathrm{a}, \mathrm{b}, \mathrm{c}\}$ with $\tau=\{\mathrm{X}, \phi,\{\mathrm{a}\},\{\mathrm{b}, \mathrm{c}\}\}$, $\sigma=\{\mathrm{Y}, \phi,\{\mathrm{a}, \mathrm{b}\}\}$ and $\eta=\{\mathrm{Z}, \phi,\{\mathrm{c}\}\}$. Let $\mathrm{f}:(\mathrm{X}, \tau) \rightarrow(\mathrm{Y}, \sigma)$ be defined by $\mathrm{f}(\mathrm{a})=\mathrm{c}, \mathrm{f}(\mathrm{b})=\mathrm{b}, \mathrm{f}(\mathrm{c})=\mathrm{a}$ and $\mathrm{g}:(\mathrm{Y}, \sigma) \rightarrow(\mathrm{Z}, \eta)$ be defined by $g(a)=a, g(b)=c, g(c)=b$. Then the maps $f$ and $\mathrm{g}$ are $\delta \mathrm{g}^{*}$-continuous but their composition $\mathrm{g} \circ \mathrm{f}:(\mathrm{X}, \tau) \longrightarrow(\mathrm{Z}, \eta)$ is not $\delta \mathrm{g}^{*}$-continuous, since for the closed set $\{a, b\}$ in $(Z, \eta),(g \circ f)^{-1}\{a, b\}=\{a, c\}$ is not $\delta g^{*}$ closed in $(X, \tau)$. 


\subsection{Proposition}

Let $\mathrm{f}:(\mathrm{X}, \tau) \longrightarrow(\mathrm{Y}, \sigma)$ be any topological space and $(\mathrm{Y}, \sigma)$ be a $\delta_{\mathrm{g}^{*}} \mathrm{~T}_{\delta}$-space. If $\mathrm{f}:(\mathrm{X}, \tau) \longrightarrow(\mathrm{Y}, \sigma)$ and $\mathrm{g}:(\mathrm{Y}, \sigma) \longrightarrow(\mathrm{Z}, \eta)$ are $\delta \mathrm{g}^{*}$-continuous maps, then their composition $\mathrm{g} \circ \mathrm{f}:(\mathrm{X}, \tau) \longrightarrow(\mathrm{Z}, \eta)$ is a $\delta \mathrm{g}^{*}$-continuous maps.

Proof: Let $\mathrm{V}$ be a closed set in $(\mathrm{Z}, \eta)$. Since g: $(\mathrm{Y}, \sigma)$ $(\mathrm{Z}, \eta)$ is $\delta \mathrm{g}^{*}$-continuous, $\mathrm{g}^{-1}(\mathrm{~V})$ is $\delta \mathrm{g}^{*}$-closed in $(\mathrm{Y}, \sigma)$. Since $(\mathrm{Y}, \sigma)$ is a ${ }_{\delta \mathrm{g} *} \mathrm{~T}_{\delta}$-space, $\mathrm{g}^{-1}(\mathrm{~V})$ is $\delta$-closed in $(\mathrm{Y}, \sigma)$. Now $g^{-1}(V)$ is closed in $(Y, \sigma)$. Since $f:(X, \tau) \quad(Y, \sigma)$ is $\delta \mathrm{g}^{*}$-continuous, $\mathrm{f}^{-1}\left(\mathrm{~g}^{-1}(\mathrm{~V})\right)=(\mathrm{g} \circ \mathrm{f})^{-1}(\mathrm{~V})$ is $\delta \mathrm{g}^{*}$-closed in $(\mathrm{X}, \tau)$. Hence $\mathrm{g} \circ \mathrm{f}:(\mathrm{X}, \tau) \longrightarrow \mathrm{Z}, \eta)$ is $\delta \mathrm{g}^{*}$-continuous.

\subsection{Proposition}

Let $\mathrm{f}:(\mathrm{X}, \tau) \longrightarrow(\mathrm{Y}, \sigma)$ be a $\delta \mathrm{g}^{*}$-continuous map. Then for every subset $A$ of $(X, \tau) f\left(\delta g^{*} \operatorname{cl}(\mathrm{A})\right) \subseteq \delta \operatorname{cl}(\mathrm{f}(\mathrm{A}))$.

Proof: Let $\mathrm{f}:(\mathrm{X}, \tau) \longrightarrow(\mathrm{Y}, \sigma)$ be a $\delta \mathrm{g}^{*}$-continuous map and A be any subset of $(\mathrm{X}, \tau)$. Then $\delta \mathrm{cl}(\mathrm{f}(\mathrm{A}))$ is a closed set in $(\mathrm{Y}, \sigma)$. Since $\mathrm{f}$ is $\delta \mathrm{g}^{*}$-continuous, we have $\mathrm{f}^{-1}(\delta \mathrm{cl}(\mathrm{f}(\mathrm{A})))$ is $\delta \mathrm{g}^{*}$-closed in $(\mathrm{X}, \tau)$. Hence $\quad \delta \mathrm{g}^{*} \mathrm{cl}\left(\mathrm{f}^{-1}(\delta \mathrm{cl}(\mathrm{f}(\mathrm{A})))\right)$ $=\mathrm{f}^{-1}(\delta \mathrm{cl}(\mathrm{f}(\mathrm{A}))) \quad$ by Proposition 3.3 .. Since $\mathrm{f}(\mathrm{A}) \subseteq \mathrm{cl}(\mathrm{f}(\mathrm{A})), \quad \mathrm{A} \subseteq \mathrm{f}^{-1}(\mathrm{f}(\mathrm{A})) \subseteq \mathrm{f}^{-1}(\delta(\mathrm{f}(\mathrm{A})))$. Hence $\mathrm{f}^{-1}(\delta \mathrm{cl}(\mathrm{f}(\mathrm{A})))$ is $\delta \mathrm{g}^{*}$-closed set containing A. By definition of $\delta \mathrm{g}^{*}$-closure, we have $\delta \mathrm{g}^{*} \operatorname{cl}(\mathrm{A}) \subseteq \mathrm{f}^{-1}(\delta \mathrm{cl}(\mathrm{f}(\mathrm{A})))$ which implies that $\mathrm{f}\left(\delta \mathrm{g}^{*} \mathrm{cl}(\mathrm{A})\right) \subseteq \delta \mathrm{cl}(\mathrm{f}(\mathrm{A}))$.

\subsection{Proposition}

Let $f:(X, \tau) \longrightarrow(Y, \sigma)$ be a map. If for each point $x \in X$ and each open set $\mathrm{V}$ in $(\mathrm{Y}, \sigma)$ containing $\mathrm{f}(\mathrm{x})$, there exists a $\delta g^{*}$ open set $U$ in $(X, \tau)$ containing $x$ such that $f(U) \subseteq V$, then for every subset $A$ of $(X, \tau), f\left(\delta g^{*} \operatorname{cl}(A)\right) \subseteq \operatorname{cl}(f(A))$.

Proof: Let $y \in f\left(\delta g^{*} \operatorname{cl}(A)\right)$. Therefore $y=f(x)$ for some $\mathrm{x} \in \delta \mathrm{g}^{*} \operatorname{cl}(\mathrm{A}) \subseteq \mathrm{X}$. Let $\mathrm{V}$ be any open set in $(\mathrm{Y}, \sigma)$ containing $\mathrm{f}(\mathrm{x})$. Then by hypothesis, there exists a $\delta \mathrm{g}^{*}$ open set $\mathrm{U}$ in $(\mathrm{X}, \tau)$ containing $\mathrm{x}$ such that $\mathrm{f}(\mathrm{U}) \subseteq \mathrm{V}$. This implies that $\mathrm{U} \cap \mathrm{A} \neq \phi$. Then $\mathrm{f}(\mathrm{U} \cap \mathrm{A}) \neq \phi$ which implies that $\mathrm{V} \cap \mathrm{f}(\mathrm{A}) \neq \phi$. Hence $\mathrm{y} \in \operatorname{cl}(\mathrm{f}(\mathrm{A}))$.

\section{CONCLUSION}

We have introduced and studied the concept of $\delta \mathrm{g}^{*}$ continuous functions using $\delta \mathrm{g}^{*}$-closed sets. The same can be extended to Bitopological spaces, Fuzzy topological spaces in the Future.

\section{REFERENCES}

[1] Abd El-Monsef, M.E., Rose Mary, S. and Lellis Thivagar, M., On $\alpha \widehat{\mathrm{g}}$-closed sets in topological spaces, Assiut University Journal of Mathematics and Computer Science, 36 (2007), 43 - 51.
[2] Arya, S.P. and Nour, T., Characterizations of S-normal spaces, Indian J. Pure. Appl. Math., 21(8) (1990), 717 719

[3] Balachandran, K., Sundaram, P. and Maki, H., On generalized continuous maps in topological spaces, Mem. Fac. Sci. Kochi Univ. Math., 12 (1991), 5 - 13.

[4] Bhattacharya, P. and Lahiri, B.K., Semi-generalized closed sets in topology, Indian J. Math., 29(1987), 375 382 .

[5] Crossley, S.G. and Hildebrand, S.K.,Semi-closure,Texas J.Sci.,22 (1971), 99-112.

[6] Devi, R., Balachandran, K., and Maki, H., On generalized $\alpha$-continuous maps and $\alpha$-generalized continuous maps, Far East J. Math., Sci., Special Volume (1997), $1-15$

[7] Dontchev, J. and Ganster, M., On $\delta$-generalized closed set s a n d T 3 / 4 - spaces, Mem. Fac. Sci. Kochi Univ. Ser. A, Math., 17 (1996), 15-31.

[8] Lellis Thivagar, M., Meera Devi, B., Some new class of functions via $\delta \mathrm{g}$ - sets, International Journal of mathematical archive, 1 (2011), 169 - 173

[9] Lellis Thivagar, M., Rose Mary, M., Remarks on contra $\alpha \widehat{g}$ - continuous functions, International Journal of Mathematics Game theory and Algebra.

[10] Lellis Thivagar, M., Meera Devi, B. and Hatir, B., $\delta \mathrm{g}$ closed sets in topological spaces, Gen. Math. Notes, 1 (2010), $17-25$.

[11] Levine, N., Semi-open sets a $\mathrm{n} d$ semi-continuity in t o p o 1 o g i c a $1 \mathrm{~s} \mathrm{p}$ a c e s, Amer. Math. Monthly, 70 (1963), $36-41$.

[12] Levine, N., Generalized c 1 o s e d sets in topology, Rend. Circ. Mat. Palermo, 19 (1970), 89 - 96.

[13] Maki, K., Devi, R. and Balachandran, K., Generalized $\alpha$ closed sets in topology, Bull. Fukuoka Uni. Ed part III, 42(1993), $13-21$

[14] Maki, K., Devi, R. and Balachandran, K., Associated topologies of generalized $\alpha$-closed sets and $\alpha$-generalized closed sets, Mem. Fac. Sci. Kochi Univ. Ser.A. Math., 15(1994), $57-63$.

[15] Mashhour, A.S., Hasanein , I.A., and EL-Deep, S.N., $\alpha$-continuous and $\alpha$-open mappings. Acta Math. Hung, 41 (1983), $213-218$.

[16] Njastad, O., On s o m e c 1 a s s e s o f nearly open sets, Pacific J Math. 15 (1965), 961 - 970.

[17] Stone, M., Application of the theory of Boolean rings to general topology, Trans. Amer. Math. Soc. 41(1937), $374-481$.

[18] Sudha, R., Sivakamasundari, K., On $\delta \mathrm{g}^{*}$-closed sets in topological spaces, International Journal of mathematica archive, 3 (2012), $1122-1230$

[19] Velicko. N.V., H-closed topological spaces. Amer. Math. Soc. Transl., 78 (1968), $103-118$. 